\title{
Why the Patient-Made Term 'Long Covid' is needed [version 1;
}

\section{peer review: 1 approved with reservations, 1 not approved]}

\author{
Elisa Perego1, Felicity Callard (D2, Laurie Stras (iD)3, Barbara Melville-Jóhannesson4, \\ Rachel Pope (i) 5 , Nisreen A. Alwan (iD) 6-8
}

\footnotetext{
${ }^{1}$ Institute of Archaeology, University College London, London, WC1H OPY, UK

${ }^{2}$ School of Geographical and Earth Sciences, University of Glasgow, Glasgow, G12 8QQ, UK

${ }^{3}$ School of Music, Humanities \& Media, University of Huddersfield, Huddersfield, West Yorkshire, HD1 3DH, UK

${ }^{4}$ Creative Informatics, University of Edinburgh, Edinburgh, EH8 9BT, UK

${ }^{5}$ Archaeology, Classics and Egyptology, University of Liverpool, Liverpool, Lancashire, L69 7WZ, UK

${ }^{6}$ Faculty of Medicine, University of Southampton, Southampton, Hampshire, SO16 6YD, UK

${ }^{7}$ NIHR Southampton Biomedical Research Centre, Southampton University Hospitals NHS Trust, Southampton, Hampshire, SO16 6YD, UK

${ }^{8}$ National Institute for Health Research Applied Research Collaboration Wessex, University of Southampton, Southampton, Hampshire, SO16 6YD, UK
}

\section{V1 First published: 24 Sep 2020, 5:224 \\ https://doi.org/10.12688/wellcomeopenres.16307.1}

Latest published: 24 Sep 2020, 5:224

https://doi.org/10.12688/wellcomeopenres.16307.1

\section{Abstract}

The patient-made term 'Long Covid' is, we argue, a helpful and capacious term that is needed to address key medical, epidemiological and socio-political challenges posed by diverse symptoms persisting beyond four weeks after symptom onset suggestive of coronavirus disease 2019 (COVID-19). An international movement of patients (which includes all six authors) brought the persistence and heterogeneity of long-term symptoms to widespread visibility. The same grassroots movement introduced the term 'Long Covid' (and the cognate term 'long-haulers') to intervene in relation to widespread assumptions about disease severity and duration. Persistent symptoms following severe acute respiratory syndrome coronavirus 2 (SARS-CoV-2) infection are now one of the most pressing clinical and public health phenomena to address: their cause(s) is/are unknown, their effects can be debilitating, and the percentage of patients affected is unclear, though likely significant. The term 'Long Covid' is now used in scientific literature, the media, and in interactions with the WHO. Uncertainty regarding its value and meaning, however, remains. In this Open Letter, we explain the advantages of the term 'Long Covid' and bring clarity to some pressing issues of use and definition. We also point to the importance of centring patient experience and expertise in relation to 'Long Covid' research, as well as the provision of care and rehabilitation.

\section{Open Peer Review

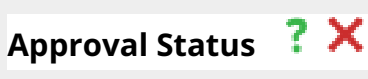 \\ 1 \\ 2 \\ version 1 \\ 24 Sep 2020

$\begin{array}{cc}? & \mathbf{X} \\ \text { view } & \text { view }\end{array}$ \\ 1. Ayo Wahlberg (iD), University of \\ Copenhagen, Copenhagen, Denmark \\ 2. Paul Garner (DD, Liverpool School of Tropical \\ Medicine, Liverpool, UK \\ Any reports and responses or comments on the article can be found at the end of the article.}




\section{Keywords}

COVID-19, Long Covid, naming of diseases, patient advocacy, patient

movements, patient-led research, SARS-CoV-2, symptoms

\section{Q. This article is included in the Coronavirus}

(COVID-19) collection.

Corresponding authors: Elisa Perego (e.perego@ucl.ac.uk), Felicity Callard (felicity.callard@glasgow.ac.uk)

Author roles: Perego E: Conceptualization, Project Administration, Writing - Original Draft Preparation, Writing - Review \& Editing; Callard F: Conceptualization, Funding Acquisition, Project Administration, Writing - Original Draft Preparation, Writing - Review \& Editing; Stras L: Writing - Original Draft Preparation, Writing - Review \& Editing; Melville-Jóhannesson B: Writing - Original Draft Preparation, Writing - Review \& Editing; Pope R: Writing - Original Draft Preparation, Writing - Review \& Editing; Alwan NA: Conceptualization, Writing - Original Draft Preparation, Writing - Review \& Editing

Competing interests: All authors have been involved in different forms of patient advocacy in relation to 'Long Covid'

Grant information: This work was supported by the Wellcome Trust through grant to Leon Rocha [219172] and Jane Macnaughton [209513].

The funders had no role in study design, data collection and analysis, decision to publish, or preparation of the manuscript.

Copyright: (c) 2020 Perego E et al. This is an open access article distributed under the terms of the Creative Commons Attribution License , which permits unrestricted use, distribution, and reproduction in any medium, provided the original work is properly cited.

How to cite this article: Perego E, Callard F, Stras L et al. Why the Patient-Made Term 'Long Covid' is needed [version 1; peer review: 1 approved with reservations, 1 not approved] Wellcome Open Research 2020, 5:224

https://doi.org/10.12688/wellcomeopenres.16307.1

First published: 24 Sep 2020, 5:224 https://doi.org/10.12688/wellcomeopenres.16307.1 


\section{Disclaimer}

The views expressed in this article are those of the authors. Publication in Wellcome Open Research does not imply endorsement by Wellcome.

\section{Introduction}

This Open Letter aims to contribute to multi-stakeholder discussions over how to conceptualize and respond to symptoms that persist several weeks after symptom onset suggestive of coronavirus disease 2019 (COVID-19). As authors, we all experience such symptoms and have contributed to international patient advocacy in relation to the acknowledgement and conceptualization of such symptoms. We also bring interdisciplinary expertise from the humanities, interpretive social sciences, arts, medicine and public health, science policy, patient involvement, and ethics in research. The Open Letter explains why we believe that the patient-made term 'Long Covid' is a helpful and capacious term that is needed to address key medical, epidemiological and socio-political challenges posed by long-term symptoms. Persistent symptoms following severe acute respiratory syndrome coronavirus 2 (SARS-CoV-2) infection are now one of the most pressing clinical and public health phenomena to address: their cause(s) is/are unknown, their effects can be debilitating, and the percentage of patients affected is unclear, though likely significant. The term 'Long Covid' has now been taken up in scientific literature, the media, and in clinical, policy, and governmental spaces. Uncertainty regarding its value and meaning, however, remains. In this Open Letter, we explain the advantages of the term 'Long Covid' and bring clarity to some pressing issues of use and definition.

\section{What is 'Long Covid'?}

'Long Covid' is a patient-made term that, in the absence of formally agreed definitions, we use here to describe diverse symptoms persisting beyond four weeks after symptom onset suggestive of COVID-19. Many patients who have remained ill for months initiated support groups and grassroots campaigns to bring the condition to visibility ${ }^{1-3}$. 'Long Covid' (and cognate 'long-haul Covid') now appears in journals ${ }^{4,5}$, and has been used by clinical and governmental actors and WHO meetings ${ }^{6-8}$. Doubts and imprecision about its meaning remain, however, and an epidemiological definition is needed. For this, two other definitions must be established: a clinical case definition of COVID-19, which does not solely rely on laboratory confirmation; and a sophisticated definition for recovery that accounts for relapsing illness ${ }^{9,10}$. Once those definitions are in place, quantifying 'Long Covid' by excluding what it is not, 'Long Covid' remains a capacious and powerful term - one that has passed from patients to use by the WHO in under three months.

'Long Covid' was first used by Perego $^{11}$ as a contraction of long-term Covid illness to engage with her experience of a cyclical, multiphasic, and multi-system condition extending - temporally and clinically - beyond a biphasic pathway identified, for example, by Lescure et al. ${ }^{12}$. The cognate term 'long haulers' was independently established by Watson for the support group she founded ${ }^{13}$, and brought to wide attention by Yong ${ }^{14}$. Exchanges amongst patients, as well as print and broadcast journalism, have been central in consolidating both terms. Patient-led surveys made visible the diversity and persistence of symptoms ${ }^{15}$; these findings are now being replicated in peer-reviewed journals ${ }^{16,17}$. Scientists do not yet know what causes long-term symptoms ${ }^{18}$ and incidence remains uncertain: case studies indicate $10-87 \%$ present persistent symptoms or fail to return to their health baseline three weeks after onset ${ }^{16,17,19}$. These figures, however, derive from heterogeneous study designs and samples.

We argue here that 'Long Covid', as an open and malleable term, has many advantages for describing persistent symptoms and/or sequelae of infection, as well as for navigating the dramatic scientific and socio-political challenges posed by the pandemic. In addition to itemizing these advantages below, we point to important considerations we believe should be kept in mind when conceptualizing and defining 'Long Covid'.

\section{Composite and multi-dimensional}

'Long Covid' points to vastly variable clinical manifestations. It may incorporate several conditions with different aetiologies and more than one mechanism, even in the same patient. Effects in multiple organs have been documented ${ }^{20,21}$. Ongoing fatigue appears common ${ }^{22-24}$. While waiting for further research, 'Long Covid' may, mechanistically, include patients with symptoms variously deriving from direct viral damage, immune response damage, opportunistic bacterial infections, and post-viral/post-sepsis symptoms ${ }^{25-27}$. Additional post-traumatic and mental health symptoms might interact with physiological symptoms in complex ways ${ }^{28,29}$. 'Long Covid' accounts for the possibility of persistent viral infection with low levels of viral shedding; protracted immune reaction; latency; or the presence of virus in reservoir organs or tissues ${ }^{27,30}$. SARS-CoV-2 also appears to be able to reinfect ${ }^{31}$, and to have the potential to precipitate new disease ${ }^{32-34}$.

'Long Covid' patients require prompt, multidimensional diagnostic investigations and treatment - not least to rule out potentially life-threatening developments ${ }^{5}$. Those who were not hospitalized, and those who were not tested or have negative PCR/antibody tests, must be able to access diagnostic and therapeutic services ${ }^{5}$. Trauma and psychological symptoms are reported in both hospitalized and non-hospitalized survivors and need to be addressed sensitively ${ }^{28}$. Differential diagnosis that does not reduce 'Long Covid' to psychological symptoms is crucial. We urge researchers and clinicians to tread a careful line which: (i) does not assume that symptoms are caused by anxiety; (ii) acknowledges that COVID-19 is frequently a traumatic experience; (iii) considers many potential mechanisms in explaining mental health symptoms - including inflammatory responses and neurological damage ${ }^{21,28,35}$.

\section{Disease severity}

'Long Covid' intervenes in early classifications of COVID-19 as mild, severe, and critical, built on reports from Wuhan ${ }^{36,37}$. 
COVID-19 was initially assumed to be a respiratory disease: classification was based around pneumonia severity and respiratory and/or multiple organ failure. It has become clear this categorisation does not do justice to heterogeneous disease trajectories. COVID-19is now primarily characterized as a multisystemic disease: mild manifestations in the prodromal stage can progress to severe disease ${ }^{12}$ and sequelae, including cardiovascular, thrombotic, and neurological manifestations $\mathrm{s}^{26,38}$. Interstitial COVID-19 pneumonia can be asymptomatic/pauci-symptomatic, challenging any easy adjudication of severity ${ }^{39}$. Heterogeneous disease pathways and comorbidities - particularly those rendering people vulnerable, e.g. dementias - are likely to make it harder to parse 'Long Covid' symptoms. Aberrant immune response might be involved in persistent symptoms and additional organ damage ${ }^{27}$. By deconstructing the current mild vs severe dichotomy, 'Long Covid' underlines that hospitalization is an imperfect indicator of severity, even if has been used as such in studies. Criteria for admission varied from country to country, and within countries, and there are indications from hotspots that severely ill patients were not hospitalized ${ }^{40,41}$. To rely on hospitalization as a demarcation of severity creates skewed samples ${ }^{9}$, including poor representation of younger/ paediatric patients ${ }^{42,43}$. In any case, persistent symptoms impairing an individual's usual function and quality of life should not be called 'mild"',37.

Other clinical arenas indicate the difficulty of assessing whether severity criteria should be based on risk of death, symptomatology, extent of impairment, or symptoms longevity ${ }^{44}$. 'Long Covid' insists that definitional resolutions need to include the perspective and published records of multiple patients with different temporal and clinical pathways. This has significant implications both for the way that individuals are medically treated and cared for, and how risk of infection is approached at a population level.

\section{Nature and duration of disease}

While we provisionally define 'Long Covid' patients as those who have not recovered within four weeks from symptom onset, the point at which COVID-19 moves out of its acute phase remains unclear, and may vary in different patients ${ }^{12,26,45}$. Duration and final outcomes of, and recovery from, 'Long Covid' are also unclear. Further research needs to address the complex host-pathogen interaction $^{46}$. While similarities between some 'Long Covid' symptoms and symptoms from conditions such as Myalgic encephalomyelitis/chronic fatigue syndrome (ME/CFS) and dysautonomia need to be investigated ${ }^{47,48}$, there is a risk of prematurely framing studies of 'Long Covid' through other diseases. This might downplay emerging phenomena specifically linked to COVID-19 - such as the range of SARS-CoV-2 action via ACE2 receptors widespread in the body, and the temporally and spatially complex immune response to the virus - thereby missing thresholds for early intervention ${ }^{25,45}$.

'Long Covid', through assuming agnosticism in relation to an as yet not understood disease course, side-steps the problems of 'post-' (e.g. 'post-Covid syndrome', 'post-acute') and 'chronic'. It advocates instead for a nuanced and personalized approach to each patient - including monitoring and intervention both early in the infection and as a follow-up ${ }^{5,45}$.

\section{Prevention and morbidity}

We need to adequately assess both morbidity and mortality in 'Long Covid' cohorts - including in those who were not tested at the time of infection or via effective serology screening, since testing is not exempt from pitfalls ${ }^{30}$. The personal, economic and social costs of 'Long Covid' are unfathomable. They include screening; medical, rehabilitative and social care; and meeting costs associated with long-term disability, including lost productivity ${ }^{49}$. Research indicating sequelae, even in asymptomatic/pauci-symptomatic cases, suggests screening and treatment may be needed for millions. The impact on already marginalised/minoritised communities will be particularly profound. 'Long Covid' calls for greater specificity in measuring 'symptom duration, fluctuation, overall functionality and quality of life in comparison to before infection' ${ }^{50}$. Understanding 'Long Covid' is also crucial for prevention, and will help determine pandemic control policies.

\section{Centring patients}

'Long Covid' was made by grassroots, international movements of people experiencing a new disease. Patients, many of them undergoing traumatic experiences in dramatic circumstances, engaged in self-reflection and observation, collective support, advocacy and activism. Many are closely involved in and engaging with fast-moving scientific literature; some are themselves clinicians and/or researchers ${ }^{9,37,50-52}$.

Patients should be involved in the commissioning of research and clinical services. Many bring relevant expertise and some convene/own patient-led archives hosting extensive clinical data.

'Long Covid' demands that medical professionals, the media and the wider community are sensitive to the trauma experienced by patients ${ }^{53}$. Some were left untended, to die at home; many were misunderstood or had their symptoms reduced to anxiety ${ }^{54}$. Some have been caring for ill - or dying - family and friends, and many have lost jobs or are under threat of losing their livelihoods, medical insurance or visa status. Patients' datasets of symptoms, and potential therapeutics, carry risks of exploitation. Rapid gathering of DNA and other data from 'Long Covid' groups poses significant ethical challenges, including the use of sensitive information shared on different media to raise awareness in an unprecedented crisis.

\section{Disability-inclusive}

'Long Covid' is explicitly disability-inclusive. Many who made 'Long Covid' - including some of us authors - have experienced disability, suffered discriminatory healthcare practices, and draw on models developed within disability activism/ research $^{55,56}$. 'Long Covid' also acknowledges the experiences of those who were healthy, or did not identify themselves as disabled/chronically ill, before infection. 'Long Covid' insists that long-term symptoms, disability, and rehabilitation 
are complex phenomena extending beyond questions of biology and physiology. They are entrenched unevenly within the socio-environmental milieu of communities ${ }^{57-60}$.

\section{The perils of pandemic medicine}

'Long Covid', with its aetiological openness, recognizes the risks inherent to emergency medicine. These include: speculative therapies; inadequate care risking persistent/permanent damage; over-hasty diagnosis and diagnostic lumping - particularly in the context of trauma in clinicians and patients; lack of access to testing and diagnostic tools; and stigma. When in-depth testing evaluating biological markers is not available, or when such tests do not explain symptoms or the exact duration of viral persistence, the risk of misdiagnosis remains high.

'Long Covid' acknowledges the potential for persistent illness to be caught up in political and medical misunderstandings and exploitation. The definition and treatment of complex phenomena ('Long Covid') that emerge in relation to an equally complex, currently not well understood disease (COVID-19), itself of contingent definition, are full of danger. We do not currently know whether all 'Long Covid' patients are indeed 'post-viral'.

Anthony Fauci has stated that a COVID-19 'post-viral syndrome' is 'strikingly similar to myalgic encephalomyelitis/chronic fatigue syndrome' ${ }^{61}$. While we acknowledge the importance of investigating comparisons with other diagnostic entities, we argue however against enfolding 'Long Covid' within other diagnoses. We need a label distinct from other phenomena related to earlier viral and other exposures (e.g. ME/ CFS). We also question the term 'Post-Covid Syndrome': we believe it carries not only risks of misdiagnoses and mismanagement, but also of leaving those with persistent illness behind, especially in a post-vaccine world.

\section{Conclusion}

The term 'Long Covid' emphasizes the only aspect of illness comprising persistent symptoms about which there is currently certainty: illness is long in relation to the prevalent early public message of two weeks of illness in mild COVID-19 cases $^{36,62}$. The simplicity and strength of 'Long Covid' as a term helps the fight for fair recognition on a global scale, and calls for care, equity, compassion, and collective action - involving prominent actors, stakeholders, and activists. It is founded on demands for a nuanced, patient-focused approach - one incorporating wide-ranging investigations of potential post-viral conditions but, crucially, recognizing the pathogenesis of SARS-CoV2 as specific in its own right. We need to avoid the severity or prevalence of 'Long Covid' being downplayed - whether for political purposes, privileging the claims that the economy is at odds with reducing levels of infection, or for fear of inadequately resourced healthcare systems ${ }^{37}$. We need to ensure the public knows about the potential 'Long Covid' consequences of infection when they are balancing the risks of exposure to SARS-CoV-2.

In coming months, it is possible some clinical sub-disciplines or research groups, might be favoured - especially if specific medical/legal definitions for those with long-term symptoms are imposed or achieved. Which patients might be left out? How will funds be allocated for research and treatment? Who will qualify for disability benefits/sick pay? How can we ensure that evidence about variation in patients is not disregarded and exacerbates inequalities?

'Long Covid' calls for collective responses to such questions, in which the expertise of 'Long Covid' patients is recognised within multi-disciplinary teams of researchers, stakeholders and care providers. Extensive involvement of 'Long Covid' patients has the best chance of ensuring that conceptualization, investigation and treatment of 'Long Covid' are attentive to the cultures, health systems, and discriminatory societies where patients live ${ }^{35,60}$. 'Long Covid' must not be understood as the outcome of biological processes alone.

\section{Data availability}

Underlying data

No data are associated with this article.

\section{Acknowledgements}

Ideas in this Open Letter have benefitted from conversations with multiple Long Covid patients and advocates in many countries. FC thanks Jane Macnaughton and Leon Rocha, principal investigators of the two grants listed, for their support.
1. LongCovidSOS: LongCovidSOS. LongCovidSOS. [cited 2020 Aug 20]. Reference Source

2. Long Covid Support Group (LongCovid.org): Long Covid. Long Covid. [cited 2020 Sep 1]. Reference Source

3. Apresj20: Apresj20: le site des Covid persistants. apresj20. [cited 2020 Sep 1] Reference Source

4. Altmann DM, Boyton RJ: SARS-CoV-2 T cell immunity: Specificity, function, durability, and role in protection. Sci Immunol. 2020; 5(49): eabd6160. PubMed Abstract | Publisher Full Text
5. Greenhalgh T, Knight M, A'Court C, et al.: Management of post-acute covid-19 in primary care. BM]. 2020 [cited 2020 Aug 12]; 370: m3026. PubMed Abstract | Publisher Full Text

6. All-Party Parliamentary Group on Coronavirus: 2nd Oral Evidence Session - All-Party Group on Coronavirus. 2020; [cited 2020 Aug 20]. Reference Source

7. World Health Organization: Covid-19 Virtual Press conference 21 August 2020. 2020.

Reference Source

8. Nath A, Jeanne Billioux B: Long-Haul Covid. World Neurology. 2020; 35(3): 1-3. 
9. Alwan N: A negative Covid-19 test does not mean recovery. Nature. 2020; 584(7820): 170.

Publisher Full Text

10. Alwan NA: Surveillance is underestimating the burden of the COVID-19 pandemic. Lancet. 2020 [cited 2020 Aug 28]; 396(10252): e24.

PubMed Abstract | Publisher Full Text

11. Perego E: Twitter. 20 May. 2020

Reference Source

12. Lescure FX, Bouadma L, Nguyen D, et al.: Clinical and virological data of the first cases of COVID-19 in Europe: a case series. Lancet Infect Dis. 2020; 20(6): 697-706.

PubMed Abstract | Publisher Full Text | Free Full Text

13. Edwards E: COVID-19 “long-haulers" report nearly $\mathbf{1 0 0}$ symptoms for more than 100 days. NBC News. 2020; [cited 2020 Jul 31].

Reference Source

14. Yong E: CovID-19 Can Last for Several Months. The Atlantic. 2020; [cited 2020 Jul 31].

Reference Source

15. Assaf G, Davis H, McCorkell L, et al.: COVID-19 Prolonged Symptoms Survey - Analysis Report. 2020; [cited 2020 Jul 31]

Reference Source

16. Carfi A, Bernabei R, Landi F: Persistent Symptoms in Patients After Acute COVID-19. JAMA. 2020 [cited 2020 Aug 6]; 324(6): 603-605. PubMed Abstract | Publisher Full Text | Free Full Text

17. Tenforde MW: Symptom Duration and Risk Factors for Delayed Return to Usual Health Among Outpatients with COVID-19 in a Multistate Health Care Systems Network - United States, March-June 2020. MMWR Morb Mortal Wkly Rep. 2020 [cited 2020 Aug 6]; 69(30): 993-998. PubMed Abstract | Publisher Full Text | Free Full Text

18. Arunachalam PS, Wimmers F, Mok CKP, et al: Systems biological assessment of immunity to mild versus severe COVID-19 infection in humans. Science. 2020 [cited 2020 Aug 12]; 369(6508): 1210-1220. PubMed Abstract | Publisher Full Text

19. COVID-19 Symptom Study App: How long does COVID-19 last? 2020; [cited 2020 Aug 19].

Reference Source

20. Puntmann VO, Carerj ML, Wieters I, et al.: Outcomes of Cardiovascular Magnetic Resonance Imaging in Patients Recently Recovered From Coronavirus Disease 2019 (COVID-19). JAMA Cardiol. 2020 [cited 2020 Aug 6]; e203557.

PubMed Abstract | Publisher Full Text | Free Full Text

21. Paterson RW, Brown RL, Benjamin L, et al.: The emerging spectrum of COVID19 neurology: clinical, radiological and laboratory findings. Brain. 2020 [cited 2020 Aug 8]; awaa240.

PubMed Abstract | Publisher Full Text | Free Full Text

22. Townsend $L$, Dyer $A H$, Jones $K$, et al.: Persistent fatigue following SARS-CoV2 infection is common and independent of severity of initial infection. medRxiv. 2020; 2020.07.29.20164293.

Publisher Full Text

23. Islam MF, Cotler J, Jason LA: Post-viral fatigue and COVID-19: lessons from past epidemics. Fatigue: Biomedicine, Health \& Behavior. 2020; 8(2): 61-69. Publisher Full Text

24. Williams FMK, Muirhead N, Pariante C: Covid-19 and chronic fatigue. BMJ. 2020 [cited 2020 Aug 6]; 370: m2922. PubMed Abstract | Publisher Full Text

25. British Society for Immunology: Long-term immunological health consequences of COVID-19. British Society for Immunology; 2020; [cited 2020 Aug 24].

Reference Source

26. Inciardi RM, Lupi L, Zaccone $G$, et al: Cardiac Involvement in a Patient With Coronavirus Disease 2019 (COVID-19). JAMA Cardiol. 2020; 5(7): 819-24. PubMed Abstract | Publisher Full Text | Free Full Text

27. Topol EJ, Verghese A, Iwasaki A: COVID Immune Responses Explained. Medscape. 2020; [cited 2020 Aug 23].

Reference Source

28. Mazza MG, De Lorenzo R, Conte C, et al.: Anxiety and depression in CoviD-19 survivors: Role of inflammatory and clinical predictors. Brain Behav Immun 2020 [cited 2020 Aug 6]; S0889-1591(20)31606-8.

PubMed Abstract | Publisher Full Text | Free Full Text

29. Troyer EA, Kohn JN, Hong S: Are we facing a crashing wave of neuropsychiatric sequelae of COVID-19? Neuropsychiatric symptoms and potential immunologic mechanisms. Brain Behav Immun. 2020; 87: 34-39. PubMed Abstract | Publisher Full Text | Free Full Text

30. Jamiolkowski $D$, Mühleisen $B$, Müller $S$, et al.: SARS-CoV-2 PCR testing of skin for COVID-19 diagnostics: a case report. Lancet. 2020 [cited 2020 Aug 27]; 396(10251): 598-599.

PubMed Abstract | Publisher Full Text | Free Full Text

31. To KKW, Hung IFN, Ip JD, et al.: COVID-19 re-infection by a phylogenetically distinct SARS-coronavirus-2 strain confirmed by whole genome sequencing. Clin Infect Dis. 2020 [cited 2020 Sep 1]; ciaa1275. PubMed Abstract | Publisher Full Text

32. Bridwell RE, Merrill DR, Griffith SA, et al.: A coronavirus disease 2019 (COVID19) patient with bilateral orchitis: A case report. Am J Emerg Med. 2020 [cited
2020 Sep 1]; S0735-6757(20)30761-0.

PubMed Abstract | Publisher Full Text | Free Full Text

33. Rubino F, Amiel SA, Zimmet $P$, et al.: New-Onset Diabetes in Covid-19. N Engl J Med. 2020; 383(8): 789-790.

PubMed Abstract | Publisher Full Text | Free Full Text

34. Unsworth R, Wallace S, Oliver NS, et al:: New-Onset Type 1 Diabetes in Children During COVID-19: Multicenter Regional Findings in the U.K. Diabetes Care. 2020 [cited 2020 Aug 27]; dc201551.

PubMed Abstract | Publisher Full Text

35. Rose N, Manning N, Bentall R, et al:: The social underpinnings of mental distress in the time of COVID-19 - time for urgent action [version 1; peer review: 4 approved]. Wellcome Open Res. 2020; 5: 166 PubMed Abstract | Publisher Full Text | Free Full Text

36. World Health Organization: Report of the WHO-China Joint Mission on Coronavirus Disease 2019 (COVID-19). World Health Organization; 2020; [cited 2020 Apr 26]. Reference Source

37. Callard F: Very, very mild: Covid-19 symptoms and illness classification. Somatosphere. 2020; [cited 2020 Jul 31]. Reference Source

38. Lu Y, Li X, Geng D, et al.: Cerebral Micro-Structural Changes in COVID-19 Patients - An MRI-based 3-month Follow-up Study. EClinicalMedicine. 2020 [cited 2020 Aug 27]; 25: 100484 PubMed Abstract | Publisher Full Text | Free Full Text

39. Bandirali M, Sconfienza LM, Serra R, et al: Chest Radiograph Findings in Asymptomatic and Minimally Symptomatic Quarantined Patients in Codogno, Italy during COVID-19 Pandemic. Radiology. 2020; 295(3): E7. PubMed Abstract | Publisher Full Text | Free Full Text

40. Anonymous: «Non solo chi ha un'età avanzata» A Bergamo 1.800 trentenni con polmonite. L'eco di Bergamo. 2020; [cited 2020 Sep 1]. Reference Source

41. Bloch-Budzier S: Fears some Covid patients "not taken to hospital". $B B C$ News. 2020; [cited 2020 Aug 6].

Reference Source

42. Götzinger F, Santiago-García B, Noguera-Julián A, et al.: COVID-19 in children and adolescents in Europe: a multinational, multicentre cohort study. Lancet Child Adolesc Health. 2020; 4(9): 653-61. PubMed Abstract | Publisher Full Text | Free Full Text

43. Perego E, Esperti M: Report from Italy on COVID-19 and persistent symptoms \#LongCovid: Report to WHO 21 August Meeting. 2020.

44. Yamamoto S, Levin HS, Prough DS: Mild, moderate and severe: terminology implications for clinical and experimental traumatic brain injury. Curr Opin Neurol. 2018; 31(6): 672-680.

PubMed Abstract | Publisher Full Text

45. Lucas $C$, Wong $P$, Klein J, et al.: Longitudinal analyses reveal immunological misfiring in severe COVID-19. Nature. 2020; 584(7821): 463-469. PubMed Abstract | Publisher Full Text | Free Full Text

46. Burn E, Tebe C, Fernandez-Bertolin S, et al.: The natural history of symptomatic COVID-19 in Catalonia, Spain: a multi-state model including 109,367 outpatient diagnoses, 18,019 hospitalisations, and 5,585 COVID-19 deaths among $5,627,520$ people. medRxiv. 2020.

Publisher Full Text

47. Eshak N, Abdelnabi M, Ball S, et al.: Dysautonomia: An Overlooked Neurological Manifestation in a Critically ill COVID-19 Patient. Am J Med SC 2020 [cited 2020 Sep 2]; S0002-9629(20): 30316-5.

PubMed Abstract | Publisher Full Text | Free Full Text

48. Perrin R, Riste $L$, Hann $M$, et al.: Into the looking glass: Post-viral syndrome post COVID-19. Med Hypotheses. 2020; 144: 110055

PubMed Abstract | Publisher Full Text | Free Full Text

49. Bartsch SM, Ferguson MC, McKinnell JA, et al.: The Potential Health Care Costs And Resource Use Associated With COVID-19 In The United States. Health Aff (Millwood). 2020; 39(6): 927-35.

PubMed Abstract | Publisher Full Text

50. Alwan N: What exactly is mild covid-19? BMJ. 2020 [cited 2020 Jul 31]. Reference Source

51. Garner P: For $\mathbf{7}$ weeks I have been through a roller coaster of ill health extreme emotions, and utter exhaustion. BMJ. 2020 [cited 2020 Jul 31]. Reference Source

52. Lokugamage A, Taylor S, Rayner C: Patients' experiences of "Iongcovid" are missing from the NHS narrative. BMJ. 2020 [cited 2020 Jul 31]. Reference Source

53. Lowenstein F: How to cover COVID-19 patients sensitively. Columbia Journalism Review. 2020 [cited 2020 Sep 1]. Reference Source

54. Moyer MW: 'Gaslighted by the Medical System': The Covid-19 Patients Left Behind. Medium. 2020 [cited 2020 Sep 1]. Reference Source

55. Hedva J: Sick Woman Theory. Mask Magazine. 2016 [cited 2020 Aug 8]. Reference Source

56. Kafer A: Feminist, Queer, Crip. 1 edition. Indiana University Press; 2013. Reference Source 
57. Nakamura K: A Disability of the Soul: An Ethnography of Schizophrenia and Mental Illness in Contemporary Japan. Cornell University Press; 2013. Reference Source

58. Shakespeare T: Disability Rights and Wrongs Revisited. Oxford and New York: Routledge; 2014 [cited 2020 Aug 27]. Reference Source

59. Shilts R: And the band played on: politics, people, and the AIDS epidemic St Martin's Press; 1988.

60. Poteat T, Millett GA, Nelson LE, et al.: Understanding COVID-19 risks and vulnerabilities among black communities in America: the lethal force of syndemics. Ann Epidemiol. 2020; 47: 1-3.

PubMed Abstract | Publisher Full Text | Free Full Text

61. Fox M: Coronavirus may cause fatigue syndrome, Fauci says. CNN. 2020 [cited 2020 Aug 3]. Reference Source

62. The Novel Coronavirus Pneumonia Emergency Response Epidemiology Team: Vital Surveillances: The Epidemiological Characteristics of an Outbreak of 2019 Novel Coronavirus Diseases (COVID-19) - China, 2020. China CDC Weekly. 2020; 2(8): 113-22.

Reference Source 


\section{Open Peer Review}

\section{Current Peer Review Status: ? $\mathrm{X}$}

\section{Version 1}

Reviewer Report 14 October 2020

https://doi.org/10.21956/wellcomeopenres.17925.r40588

(c) 2020 Garner P. This is an open access peer review report distributed under the terms of the Creative Commons Attribution License, which permits unrestricted use, distribution, and reproduction in any medium, provided the original work is properly cited.

\section{Paul Garner}

Centre for Evidence Synthesis in Global Health, Liverpool School of Tropical Medicine, Liverpool, UK

1. Information about Covid-19 as the pandemic struck the UK was confined to a single WHO Report that stated the median time from onset to recovery for mild disease was two weeks and 3-6 weeks for people with severe or critical disease.

2. Long covid is a term that came about as a result of a large number of people reporting symptoms that persisted for weeks, sometimes months. It was particularly striking because people who expected a mild illness and had not been hospitalised-and were often previously fit and well-suffered these symptoms. This includes myself.

3. These seem to be a combination of post-viral symptoms associated with a number of other viral illnesses: POTS, exhaustion/fatigue being common, brain fog. There are also other post-viral effects on the heart and other organs that are just emerging.

4. There is also a worry with late complications of Covid-19 infection, including strokes and PE. The abstract

1. I would argue that "their causes are unknown". We know the cause: covid-19 infection, and many symptoms are very similar to other post viral syndromes.

2. I would argue a keyword should be "post-viral syndrome": mainly to ensure we don't start reinventing conditions that have been previously recognised and treated by infectious disease specialists and others.

Introduction

1. It is a good idea to have a capacious term, but I would be careful about researchers from the social science and public health areas defining a condition medically. Why not have it as a good holding term whilst further research on its causes and management is carried out?

2. I am concerned personally, as part of Long Covid as a patient, of defining something 
because I am fundamentally conflicted as I have the disease as an entity. A good holding term-yes; a permanent medical definition - no. The clinicians need more time to sort this out-but you may be able to stop them calling it a syndrome. So please make this stronger perhaps!

3. I am also concerned about the implication in the term Long Covid that it is caused by persistent Covid-19 infection. It's not but to the person on the street this is what it sounds like and there will be permanent confusion in the public about whether people with Long Covid are infectious. We know that this is mainly a post-viral phenomenon. The term however suggest PERSISTING INFECTION. We don't call people with glandular fever still symptomatic at 9 months as "Long Glandular Fever". We know by the nature of the disease that this is the natural history of the disease-it lasts a long time in some people. So maybe covid is like EBV-in some people there is a post viral phase that last for years.

4. There is also an issue about when the disease moves from "short" to "long". The authors state this is at four weeks, when "covid-19 moves out of its acute phase". So in a sense they are answering their own question, this is after the primary viral infection; if this is the case then it is by definition, a postviral syndrome.

5. Again I agree about not framing it automatically with ME/CFS, but most ME/CFS is postviral. I certainly agree with the nuanced and individualised approach to patient care.

6. I totally agree with measuring this somehow.

7. The disability could be expanded on. What disability are we talking about it. This needs to be made clear. What is the evidence for discriminatory health care practices? Whilst I agree with this, you need examples to make this cogent and believable.

\section{Summary}

1. I agree long covid avoids political/medical misunderstandings, BUT when the various causes are untangled-postviral effects on the immune system, brain, lung, heart-then it will be a bit clearer. And I agree having another "syndrome" specific to Covid would be extremely counterproductive. But I am still not convinced this is just simply a set of symptoms in a virus causing damage and long lasting effects that are seen with other viruses. The authors do indeed start moving to this in the second to last paragraph.

2. So all in all a reasonable advocacy summary, well written, but we need to be careful that it doesn't do exactly what it is trying to avoid-creating a new phenomenon. This is a temporary holding approach as we move forward to ensure a collective action between health care professionals, researchers and society to assure people are helped in a nondiscriminatory way, and that "no-one is left behind".

In summary, they need to be more explicit about the link between Long Covid and how this may be a postviral syndrome as seen with other diseases. I would recommend but not insist that they see it as a good "holding term" pending further elucidation of the causes of it in the team as patients and others.

\section{Is the rationale for the Open Letter provided in sufficient detail?}


Partly

Does the article adequately reference differing views and opinions?

Partly

Are all factual statements correct, and are statements and arguments made adequately supported by citations?

Partly

Is the Open Letter written in accessible language?

Yes

Where applicable, are recommendations and next steps explained clearly for others to follow?

Partly

Competing Interests: I am sick with Long Covid at 7 months

Reviewer Expertise: epidemiology and public health

I confirm that I have read this submission and believe that I have an appropriate level of expertise to state that I do not consider it to be of an acceptable scientific standard, for reasons outlined above.

Reviewer Report 09 October 2020

https://doi.org/10.21956/wellcomeopenres.17925.r40590

(C) 2020 Wahlberg A. This is an open access peer review report distributed under the terms of the Creative Commons Attribution License, which permits unrestricted use, distribution, and reproduction in any medium, provided the original work is properly cited.

\section{Ayo Wahlberg}

Department of Anthropology, University of Copenhagen, Copenhagen, Denmark

This is an important call to epidemiologically and medically normalize "Long Covid" following its grassroots emergence as a term used on various social media platforms by persons reaching out to similar others at a time where COVID-19 was solely known as either dangerously acute (for especially elderly and persons living with chronic conditions) or mild with quick recovery (for most others). This simple understanding of COVID-19 jarred with the experiences of thousands if not hundreds of thousands of people who had a confirmed diagnosis of COVID-19 or who had had symptoms without confirmation in the first half of 2020 yet who did not make a full recovery for weeks or months afterwards. Against this backdrop, the authors' Open Letter reads as a strong and convincing call for action: "Persistent symptoms following severe acute respiratory syndrome coronavirus 2 (SARS-CoV-2) infection are now one of the most pressing clinical and public health phenomena to address: their cause(s) is/are unknown, their effects can be debilitating, and the 
percentage of patients affected is unclear, though likely significant."

The key arguments of the authors is that 1) we need the term 'Long Covid', 2) we need to keep it open such that it remains an inclusive term, and 3) that it is preferable to 'post Viral syndrome' or 'Post Covid syndrome'. In their words: "'Long Covid', through assuming agnosticism in relation to an as yet not understood disease course, side-steps the problems of 'post-' (e.g. 'post-Covid syndrome', 'post-acute') and 'chronic'. It advocates instead for a nuanced and personalized approach to each patient - including monitoring and intervention both early in the infection and as a follow-up."

While I do agree with the authors that we need the term Long Covid for the reasons they outline, I nevertheless would suggest that they look to and acknowledge more explicitly the important work that medical anthropologists, medical sociologists and other qualitative health researchers have carried out over the past decades focusing on how people (and their families) live with long term conditions. Long Covid has emerged as a form of 'chronic living' for so many people in the wake of the pandemic. What we know from research on chronic living is that when people fall ill and struggle to get better, they (and their loved ones): search for meaning, look for explanations, devise coping strategies, mobilize therapy support groups, embark on therapeutic itineraries, try out a plurality of medical modalities in their search for something that 'works', innovatively adjust and tinker with the daily routines and the treatment regimens they follow, form bio-social communities to generate political attention to 'their disease', become biological citizens as they negotiate access to entitlements and demand health rights by tactically using biological knowledge. There are so many authors to acknowledge here, I can recommend Lenore Manderson \& Carolyn Smith-Morris on "Chronic Conditions, Fluid States", Jeanette Pols on "patient knowledge", Arseli Dokumaci on "the disabilitisation of medicine", Natasja Kingod on the "tinkering m-patient", Jieun Lee on paradoxical forms of "living with/out", Marie Svensson's work on "chronic paradoxes" and my own together with Nikolas Rose on "the governmentalisation of living" as "the social and personal consequences of living with disease come to be an object of political concern, and made knowable, calculable and thereby amenable to various strategies of intervention". There are so many more relevant references!

If there is a moment to hammer home the crucial relevance of the social sciences/humanities in healthcare then surely Long Covid is that moment. This, for me, is what underpins the argument being made in this important open letter.

\section{Is the rationale for the Open Letter provided in sufficient detail?}

Yes

Does the article adequately reference differing views and opinions?

Yes

Are all factual statements correct, and are statements and arguments made adequately supported by citations?

Yes

Is the Open Letter written in accessible language?

Yes 
Where applicable, are recommendations and next steps explained clearly for others to follow?

Partly

Competing Interests: No competing interests were disclosed.

Reviewer Expertise: medical anthropology, medical science and technology studies

I confirm that I have read this submission and believe that I have an appropriate level of expertise to confirm that it is of an acceptable scientific standard, however I have significant reservations, as outlined above. 